\title{
Approximation of Corrected Calcium Concentrations in Advanced Chronic Kidney Disease Patients with or without Dialysis Therapy
}

\author{
Yoshio Kaku Susumu Ookawara Haruhisa Miyazawa Kiyonori Ito \\ Yuichiro Ueda Keiji Hirai Taro Hoshino Honami Mori Izumi Yoshida \\ Yoshiyuki Morishita Kaoru Tabei \\ Division of Nephrology, First Department of Integrated Medicine, Saitama Medical Center, \\ Jichi Medical University, Saitama, Japan
}

Key Words

Acid-base metabolism · Albumin · Calcium · Chronic kidney disease · Phosphate

\begin{abstract}
Background: The following calcium (Ca) correction formula (Payne) is conventionally used for serum Ca estimation: corrected total Ca $(\mathrm{TCa})(\mathrm{mg} / \mathrm{dl})=\mathrm{TCa}(\mathrm{mg} / \mathrm{dl})+[4-$ albumin $(\mathrm{g} / \mathrm{dl})]$; however, it is inapplicable to advanced chronic kidney disease (CKD) patients. Methods: 1,922 samples in CKD G4 + G5 patients and 341 samples in CKD G5D patients were collected. Levels of TCa $\left(\mathrm{mg} /\right.$ day), ionized $\mathrm{Ca}^{2+}\left(\mathrm{iCa}^{2+}\right)(\mathrm{mmol} / \mathrm{l})$ and other clinical parameters were measured. We assumed the corrected TCa to be equal to eight times the $\mathrm{iCa}^{2+}$ value (measured corrected TCa). We subsequently performed stepwise multiple linear regression analysis using the clinical parameters. Results: The following formula was devised from multiple linear regression analysis. For CKD G4 + G5 patients: approximated corrected TCa $(\mathrm{mg} / \mathrm{dl})=\mathrm{TCa}+0.25 \times$ $(4-$ albumin $)+4 \times(7.4-\mathrm{pH})+0.1 \times(6-\mathrm{P})+0.22$. For CKD G5D patients: approximated corrected $\mathrm{TCa}(\mathrm{mg} / \mathrm{dl})=\mathrm{TCa}+0.25 \times(4-$ albumin $)+0.1 \times(6-\mathrm{P})+0.05 \times\left(24-\mathrm{HCO}_{3}{ }^{-}\right)+0.35$. Receiver operating characteristic analysis showed the high values of the area under the curve of approximated corrected TCa for the detection of measured corrected TCa $\geq 8.4 \mathrm{mg} / \mathrm{dl}$ and $\leq 10.4 \mathrm{mg} / \mathrm{dl}$ for each CKD sample. Both intraclass correlation coefficients for each CKD sample demonstrated superior agreement using the new formula compared to the previously reported formulas. Conclusion: Compared to other formulas, the approximated corrected TCa values calculated from the new formula for patients with CKD G4 + G5 and CKD G5D demonstrates superior agreement with the measured corrected TCa.


Kaku et al.: Approximation of Corrected Calcium Concentrations in Advanced Chronic Kidney Disease Patients with or without Dialysis Therapy

\section{Introduction}

Measurements of serum calcium (Ca) concentration have been performed routinely to diagnose various diseases including bone and mineral disorders. Moreover, serum $\mathrm{Ca}$ is one of the most important aspects of blood biochemistry examination. Serum Ca concentrations are usually corrected by using serum albumin concentrations [1]. This method for serum Ca correction is broadly accepted in the clinical setting.

Chronic kidney disease (CKD) is commonly complicated by disorders of Ca and phosphorus metabolism [2]. Endocrine abnormalities, including these disorders of metabolism, are associated with increased cardiovascular events and mortality risk [3-7]. Therefore, recommendations on the target levels and treatment strategies for correcting serum $\mathrm{Ca}$, phosphate (P) and parathyroid hormone concentrations based on the National Kidney Foundation Kidney Disease Outcomes Quality Initiative (NKF KDOQI) and the Kidney Disease: Improving Global Outcomes (KDIGO) clinical practice guidelines were issued to prevent cardiovascular disease and death $[8,9]$. However, poor independent associations between serum levels of Ca and parathyroid hormone as well as the risks of cardiovascular events and death in CKD patients have been recently reported [10]. Furthermore, the associations between disorders of bone and mineral metabolism, with the exception of hyperphosphatemia, and cardiovascular events and mortality risks have also remained controversial. Although the reasons for the differences in results among studies are unclear, it is possible that the total $\mathrm{Ca}(\mathrm{TCa})$ concentrations corrected by using albumin concentrations do not reflect the actual TCa concentrations in patients with CKD. Indeed, in Payne's original study, specimens from the Department of Renal Medicine were excluded from analysis [1]. Additionally, several studies demonstrated a poor correlation between the corrected TCa values obtained by using the Payne formula and the gold standard for TCa determinations derived from ionized $\mathrm{Ca}^{2+}\left(\mathrm{iCa}^{2+}\right)$ values in advanced CKD patients $[11,12]$. In hemodialysis (HD) patients, several formulas that use only albumin [11-13] or albumin and P [14] for correction have been reported to more accurately predict corrected TCa concentrations compared to the Payne formula. However, it was recently reported that corrected TCa concentrations obtained by using serum albumin cannot accurately predict $\mathrm{iCa}^{2+}$ in patients with stage $3-5 \mathrm{CKD}$, and that low plasma $\mathrm{pH}$ is an independent factor for underestimation of corrected TCa [15]. To date, only a few studies have reported formulas for predicting corrected TCa in advancedstage CKD patients. Therefore, the aims of this study were (1) to develop a new formula for the approximation of corrected TCa by using clinical parameters for advanced-stage CKD patients who were on dialysis and not on dialysis, respectively, and (2) to compare the measured corrected TCa values calculated by using $\mathrm{iCa}^{2+}$, previously published formulas and the new formula reported in this study.

\section{Patients and Methods}

\section{Patients and Study Design}

This retrospective study included 822 patients (556 men and 266 women, mean age 66.0 \pm 12.2 years) who met the following criteria: (1) patients categorized as having CKD G4 to G5D according to the CKD guidelines edited by the Japanese Society of Nephrology [16] at the Division of Nephrology, Saitama Medical Center, Jichi Medical University between January 2006 and December 2010; (2) patients with serum biochemical measurements including TCa and $\mathrm{iCa}^{2+}$ concentration.

The 822 patients were divided into two groups according to CKD stage. There were 493 and 329 patients in G4 + G5 and G5D (318 on HD, 11 on peritoneal dialysis), respectively. This 
Kaku et al.: Approximation of Corrected Calcium Concentrations in Advanced Chronic Kidney Disease Patients with or without Dialysis Therapy

Table 1. Demographic and clinical characteristics of patients with CKD G4 + G5 and CKD G5D

\begin{tabular}{lcccc}
\hline CKD grade & G4 & G5 & G4 + G5 & G5D \\
Number & 149 & 344 & 493 & 329 \\
Samples & 326 & 1,596 & 1,922 & 341 \\
Variables & & & & \\
$\quad$ Age, years & $66.9 \pm 12.5$ & $66.0 \pm 12.6$ & $66.3 \pm 12.6$ & $65.7 \pm 11.5$ \\
$\quad$ Females/males & $38 / 111$ & $128 / 216$ & $166 / 327$ & $100 / 229$ \\
With diabetes/without diabetes & $41 / 108$ & $143 / 201$ & $184 / 309$ & $161 / 168$ \\
P binder use, $\mathrm{n}(\%)$ & $5(3.4)$ & $85(24.7)$ & $90(18.3)$ & $183(55.6)$ \\
Vitamin D metabolite use, n (\%) & $23(15.4)$ & $129(37.5)$ & $152(30.8)$ & $92(30.0)$ \\
Thiazide use, $\mathrm{n}(\%)$ & $9(6.0)$ & $53(15.4)$ & $62(12.6)$ & $30(9.1)$ \\
Loop diuretics, n (\%) & $63(42.3)$ & $194(56.4)$ & $257(52.1)$ & $129(39.2)$ \\
Steroids, $\mathrm{n}(\%)$ & $10(6.7)$ & $18(5.2)$ & $28(6.7)$ & $16(4.9)$ \\
Bisphosphonates, $\mathrm{n}(\%)$ & $1(0.7)$ & $2(0.6)$ & $3(0.6)$ & $1(0.3)$ \\
Cinacalcet hydrochloride use, n (\%) & $0(0)$ & $0(0)$ & $0(0)$ & $8(2.4)$ \\
\hline
\end{tabular}

study was approved by the institutional review board of Saitama Medical Center, Jichi Medical University, Saitama, Japan and conforms to the provisions of the Declaration of Helsinki (as revised in Tokyo in 2004).

1,922 blood samples in patients with G4 + G5 and 341 samples in those with G5D were collected in this study. Venous samples were collected from a native vein at the cubitus area of patients with CKD G4 to G5 who were not on HD and of patients with CKD G5D who were on peritoneal dialysis. Meanwhile, arterial venous samples from CKD G5D patients were collected from the fistula before HD. Blood samples for biochemical, hemoglobin ( $\mathrm{Hb}), \mathrm{pH}$ and $\mathrm{iCa}^{2+}$ measurements were collected in tubes with silica and thrombin (used for rapid coagulation), EDTA-2K and lithium heparin tubes, respectively. $\mathrm{iCa}^{2+}(\mathrm{mmol} / \mathrm{l})$ and $\mathrm{pH}$ were analyzed within 20 min using ion-selective electrodes in a blood gas analyzer. Biochemical parameters including $\mathrm{Hb}$, total protein, serum albumin, blood urea nitrogen (BUN), serum creatinine, sodium, potassium, chloride, $\mathrm{P}$ and TCa were measured in our hospital laboratory. In addition, we analyzed the sociodemographic data of patients, including age, presence or absence of diabetes mellitus, and treatment influencing Ca and $\mathrm{P}$ metabolism, including $\mathrm{P}$ binders, vitamin D metabolites, thiazides, loop diuretics, steroids, bisphosphonates and cinacalcet hydrochloride (table 1). We calculated the estimated glomerular filtration rate (eGFR) by using the following equation [16]: for men: eGFR $\left(\mathrm{ml} / \mathrm{min} / 1.73 \mathrm{~m}^{2}\right)=194 \times \mathrm{S}^{-} \mathrm{Cr}^{-1.094} \times$ age $^{-0.287}$; for women: eGFR $=194 \times \mathrm{S}_{-} \mathrm{Cr}^{-1.094} \times$ age $^{-0.287} \times 0.739$, where S-Cr is the serum creatinine concentration $(\mathrm{mg} / \mathrm{dl})$.

Serum Ca is either bound to plasma protein (40\%), chelated to serum anions (nearly $10 \%)$ or exists as free $\mathrm{iCa}^{2+}$ (nearly $50 \%$ ) $[17,18]$. On the basis of these results, we converted the unit of Ca concentration from $\mathrm{iCa}^{2+}(\mathrm{mmol} / \mathrm{l})$ to $\mathrm{TCa}(\mathrm{mg} / \mathrm{dl})$ by using the following equation: $\mathrm{TCa}=\mathrm{iCa}^{2+} \times 8$. Furthermore, previous reports assumed the gold standard for TCa (corrected $\mathrm{TCa}, \mathrm{mg} / \mathrm{dl}$ ) to be equal to eight times the $\mathrm{iCa}^{2+}$ value $[11,12]$. Therefore, in this study, we termed this value 'measured corrected TCa' (normal range in our laboratory derived from normal individuals: $8.4-10.4 \mathrm{mg} / \mathrm{dl}$ ). We separately examined the correlations between the measured corrected TCa and clinical parameters using a simple linear regression analysis in patients with G4 + G5 and those with G5D. Furthermore, we performed stepwise multiple linear regression analysis using variables that showed a significant correlation with the measured corrected TCa in a simple linear regression analysis in G4 + G5 and G5D patients. On the basis of the results, we devised a simple formula for corrected TCa approximation and determined the correlation between the value derived from the new formula and the measured 
corrected TCa in each of the two groups. Furthermore, intraclass correlation coefficients (ICCs) were used to assess the level of agreement between the measured corrected TCa and the new formula as well as four other previously reported formulas, respectively.

\section{Prediction of Corrected TCa}

Four different previously reported formulas were used to predict the corrected TCa. Formula 1 (Payne) [1]: corrected TCa $(\mathrm{mg} / \mathrm{dl})=\mathrm{TCa}(\mathrm{mg} / \mathrm{dl})+[4-$ serum albumin $(\mathrm{g} / \mathrm{dl})]$. Formula 2 (Jain) [12]: corrected $\mathrm{TCa}(\mathrm{mg} / \mathrm{dl})=\mathrm{TCa}(\mathrm{mg} / \mathrm{dl})+0.8 \times[3-$ serum albumin $(\mathrm{g} / \mathrm{dl})]$. Formula 3 (Portale) [13]: corrected $\mathrm{TCa}=\mathrm{TCa}(\mathrm{mg} / \mathrm{dl})+0.8 \times[4-$ serum albumin $(\mathrm{g} / \mathrm{dl})]$. Formula 4 (Ferrari) [14]: corrected TCa $(\mathrm{mg} / \mathrm{dl})=\mathrm{TCa}(\mathrm{mg} / \mathrm{dl})+1.6 \times[4-$ serum albumin $(\mathrm{g} / \mathrm{dl})]+0.56 \times[1.5-0.32 \times \mathrm{P}(\mathrm{mg} / \mathrm{dl})]$.

\section{Statistics}

Data were expressed as mean \pm standard deviation. Correlations between two values were evaluated by using Pearson's correlation coefficients and linear regression analysis. The measured corrected TCa, the corrected TCa derived from previously reported formulas and approximated corrected TCa values were compared by using one-way analysis of variance followed by Scheffé's post hoc test. Receiver operating characteristic (ROC) curves were performed to confirm the efficacy of approximated corrected TCa for the detection of measured corrected TCa and the data were expressed as the area under the curve (AUC). The ICC describes the ratio of variance due to patient differences to total variance; it ranges from 0 to 1 , where 0 indicates complete unreliability and 1 signifies perfect agreement. A difference with a $\mathrm{p}$ value $<0.05$ was considered statistically significant.

\section{Results}

The patients' demographic and clinical characteristics are shown in table 1 . The mean age of patients with CKD G4 + G5 was $66.3 \pm 12.6$ years. There were 184 and 309 patients with CKD caused by diabetes mellitus and renal disease other than diabetes mellitus, respectively. The mean age of CKD G5D patients was $65.7 \pm 11.5$ years. There were 161 and 168 patients with CKD caused by diabetes mellitus and renal disease other than diabetes mellitus, respectively. The proportions of patients using $\mathrm{P}$ binder, vitamin D metabolites, thiazides, loop diuretics, steroids, bisphosphonates and cinacalcet hydrochloride in CKD G4 + G5 were 18.3, $30.8,12.6,52.1,6.7,0.6$ and $0 \%$, respectively, and those in CKD G5D were 55.6, 30.0, 9.1, 39.2, $4.9,0.3$ and $2.4 \%$, respectively.

Table 2 shows the correlations between measured corrected TCa and clinical parameters from a simple linear regression analysis. In samples with CKD G4 + G5, measured corrected TCa was significantly and positively correlated with $\mathrm{HCO}_{3}{ }^{-}, \mathrm{Hb}$, total protein, serum albumin, sodium, potassium, chloride and TCa. In addition, it was significantly and negatively correlated with age, $\mathrm{pH}, \mathrm{BUN}$, creatinine and $\mathrm{P}$. On the other hand, in samples with CKD G5D, the measured corrected TCa was significantly and positively correlated with $\mathrm{HCO}_{3}{ }^{-}, \mathrm{Hb}$, total protein, serum albumin, creatinine and TCa, and negatively correlated with BUN and P.

In order to develop an approximated corrected TCa formula based on the measured corrected TCa values, we performed a stepwise multiple linear regression analysis using variables that showed a significant correlation with the measured corrected TCa in a simple linear regression analysis for each patient group (G4 + G5 patients) (table 3). Thus, we obtained the following simple formula for corrected TCa approximation: approximated corrected TCa $(\mathrm{mg} / \mathrm{dl})=36.6+0.79 \times \mathrm{TCa}-4.45 \times \mathrm{pH}-0.27 \times$ albumin $(\mathrm{g} / \mathrm{dl})-0.1 \times \mathrm{P}$. 
Kaku et al.: Approximation of Corrected Calcium Concentrations in Advanced Chronic Kidney Disease Patients with or without Dialysis Therapy

Table 2. Simple linear correlations between the measured corrected TCa and clinical parameters of patients with CKD G4 + G5 (n= 1,922) and CKD G5D (n = 341)

\begin{tabular}{|c|c|c|c|c|c|c|}
\hline \multirow[t]{3}{*}{ Variable } & \multicolumn{3}{|c|}{ CKD grade G4 + G5 } & \multicolumn{3}{|c|}{ CKD grade G5D } \\
\hline & \multirow[t]{2}{*}{ mean $\pm \mathrm{SD}$} & \multicolumn{2}{|c|}{ vs. measured corrected TCa } & \multirow[t]{2}{*}{ mean $\pm \mathrm{SD}$} & \multicolumn{2}{|c|}{ vs. measured corrected TCa } \\
\hline & & $\mathrm{r}$ & $\mathrm{p}$ & & $\mathrm{r}$ & $\mathrm{p}$ \\
\hline $\mathrm{pH}$ & $7.32 \pm 0.06$ & -0.18 & $<0.0001$ & $7.36 \pm 0.06$ & -0.03 & 0.56 \\
\hline $\mathrm{HCO}_{3}{ }^{-}, \mathrm{mEq} / \mathrm{l}$ & $21.8 \pm 3.9$ & 0.10 & $<0.0001$ & $21.5 \pm 3.8$ & 0.13 & 0.02 \\
\hline $\mathrm{Hb}, \mathrm{g} / \mathrm{dl}$ & $9.8 \pm 1.6$ & 0.32 & $<0.0001$ & $9.5 \pm 1.5$ & 0.23 & $<0.0001$ \\
\hline Total protein, g/dl & $6.6 \pm 0.8$ & 0.26 & $<0.0001$ & $6.2 \pm 0.7$ & 0.15 & $<0.01$ \\
\hline Serum albumin, g/dl & $3.6 \pm 0.7$ & 0.27 & $<0.0001$ & $3.1 \pm 0.6$ & 0.15 & $<0.01$ \\
\hline BUN, mg/dl & $56.6 \pm 22.4$ & -0.19 & $<0.0001$ & $56.6 \pm 20.4$ & -0.19 & $<0.0001$ \\
\hline Creatinine, mg/dl & $6.3 \pm 3.2$ & -0.12 & $<0.0001$ & $8.5 \pm 3.1$ & 0.20 & $<0.0001$ \\
\hline $\mathrm{Na}, \mathrm{mEq} / \mathrm{l}$ & $137.9 \pm 3.9$ & 0.10 & $<0.0001$ & $136.1 \pm 4.4$ & -0.05 & 0.37 \\
\hline $\mathrm{K}, \mathrm{mEq} / \mathrm{l}$ & $4.7 \pm 0.8$ & 0.10 & $<0.0001$ & $4.2 \pm 0.8$ & -0.01 & 0.92 \\
\hline $\mathrm{Cl}, \mathrm{mEq} / \mathrm{l}$ & $106.1 \pm 5.4$ & 0.11 & $<0.0001$ & $102.9 \pm 4.9$ & -0.10 & 0.06 \\
\hline $\mathrm{TCa}, \mathrm{mg} / \mathrm{dl}$ & $8.55 \pm 0.87$ & 0.76 & $<0.0001$ & $8.50 \pm 1.10$ & 0.83 & $<0.0001$ \\
\hline $\mathrm{P}, \mathrm{mg} / \mathrm{dl}$ & $4.8 \pm 1.4$ & -0.30 & $<0.0001$ & $4.7 \pm 1.6$ & -0.19 & $<0.01$ \\
\hline
\end{tabular}

Table 3. Stepwise multiple linear regression analysis using variables that demonstrated a significant correlation with the measured corrected TCa in the simple linear regression analysis of patients with CKD G4 + G5

\begin{tabular}{llll}
\hline Variable & Coefficient & Standardized coefficient & $\mathrm{p}$ \\
\hline Constant & 36.6 & & $<0.0001$ \\
TCa & 0.79 & 0.85 & $<0.0001$ \\
pH & -4.45 & -0.33 & $<0.0001$ \\
Albumin & -0.27 & -0.24 & $<0.0001$ \\
P & -0.10 & -0.17 & $<0.0001$ \\
\hline
\end{tabular}

Table 4. Stepwise multiple linear regression analysis using variables that demonstrated a significant correlation with the measured corrected TCa in the simple linear regression analysis of patients with CKD G5D

\begin{tabular}{llll}
\hline Variable & Coefficient & Standardized coefficient & $\mathrm{p}$ \\
\hline Constant & 4.0 & & $<0.0001$ \\
TCa & 0.83 & 0.90 & $<0.0001$ \\
Albumin & -0.26 & -0.16 & $<0.0001$ \\
$\mathrm{P}$ & -0.07 & -0.12 & $<0.0001$ \\
$\mathrm{HCO}_{3}{ }^{-}$ & -0.03 & -0.11 & $<0.0001$ \\
\hline
\end{tabular}

Using the mean values of TCa, $\mathrm{pH}$, albumin and P from CKD G4 + G5 samples and inputting them into the model, we simplified the original formula into the following final formula. Formula 5: approximated corrected $\mathrm{TCa}(\mathrm{mg} / \mathrm{dl})=\mathrm{TCa}+0.25 \times(4-$ albumin $)+4 \times(7.4-\mathrm{pH})$ $+0.1 \times(6-\mathrm{P})+0.22$. CKD G5D samples (table 4): approximated corrected $\mathrm{TCa}(\mathrm{mg} / \mathrm{dl})=$ $4.0+0.83 \times \mathrm{TCa}-0.26 \times$ albumin $(\mathrm{g} / \mathrm{dl})-0.07 \times \mathrm{P}-0.03 \times \mathrm{HCO}_{3}{ }^{-}$.

Using the mean values of TCa, albumin, $\mathrm{P}$ and $\mathrm{HCO}_{3}{ }^{-}$from the CKD G5D samples and inputting them into the model, we simplified the original formula into the following final formula. Formula 6: approximated corrected $\mathrm{TCa}(\mathrm{mg} / \mathrm{dl})=\mathrm{TCa}+0.25 \times(4-$ albumin $)+$ $0.1 \times(6-\mathrm{P})+0.05 \times\left(24-\mathrm{HCO}_{3}^{-}\right)+0.35$.

In the analysis of CKD G4 + G5 samples, as shown in figure 1, a positive linear correlation was observed between the measured corrected TCa and the approximated corrected TCa 
Fig. 1. Relationship between measured corrected TCa and approximated corrected TCa calculated using formula 5. A significant positive linear correlation was identified from 1,922 samples of CKD G4 + G5 patients.
Fig. 2. ROC curves of sensitivity and specificity of approximated corrected TCa for detecting measured corrected TCa $\geq 8.4 \mathrm{mg} / \mathrm{dl}$ (a) and $\leq 10.4 \mathrm{mg} / \mathrm{dl}$ (b) from 1,922 samples of CKD G4 + G5 patients.
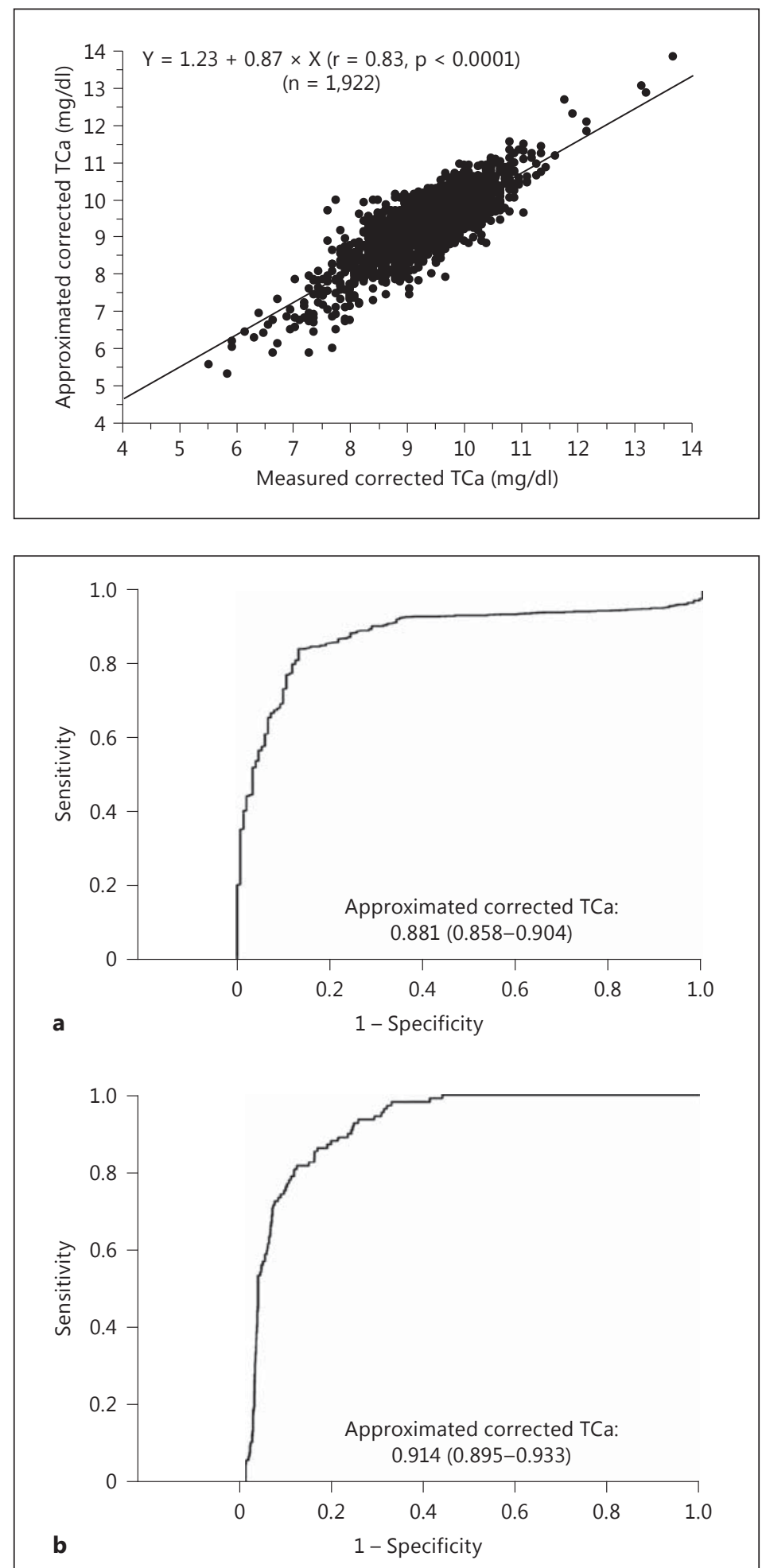

calculated by using formula $5(\mathrm{r}=0.83, \mathrm{p}<0.0001)$. ROC analysis illustrated that the AUC of approximated corrected TCa for the detection of measured corrected TCa $\geq 8.4 \mathrm{mg} / \mathrm{dl}$ and $\leq 10.4 \mathrm{mg} / \mathrm{dl}$ was 0.881 and 0.914 , respectively (fig. 2). In the analysis of CKD G5D samples, as shown in figure 3, a positive linear correlation was observed between the measured 
Kaku et al.: Approximation of Corrected Calcium Concentrations in Advanced Chronic Kidney Disease Patients with or without Dialysis Therapy

Fig. 3. Relationship between measured corrected TCa and approximated corrected TCa calculated using formula 6. A significant positive linear correlation was identified from 341 samples of CKD G5D patients.

Fig. 4. ROC curves of the sensitivity and specificity of approximated corrected TCa for detecting measured corrected TCa $\geq 8.4$ $\mathrm{mg} / \mathrm{dl}$ (a) and $\leq 10.4 \mathrm{mg} / \mathrm{dl}$ (b) from 341 samples of CKD G5D patients.
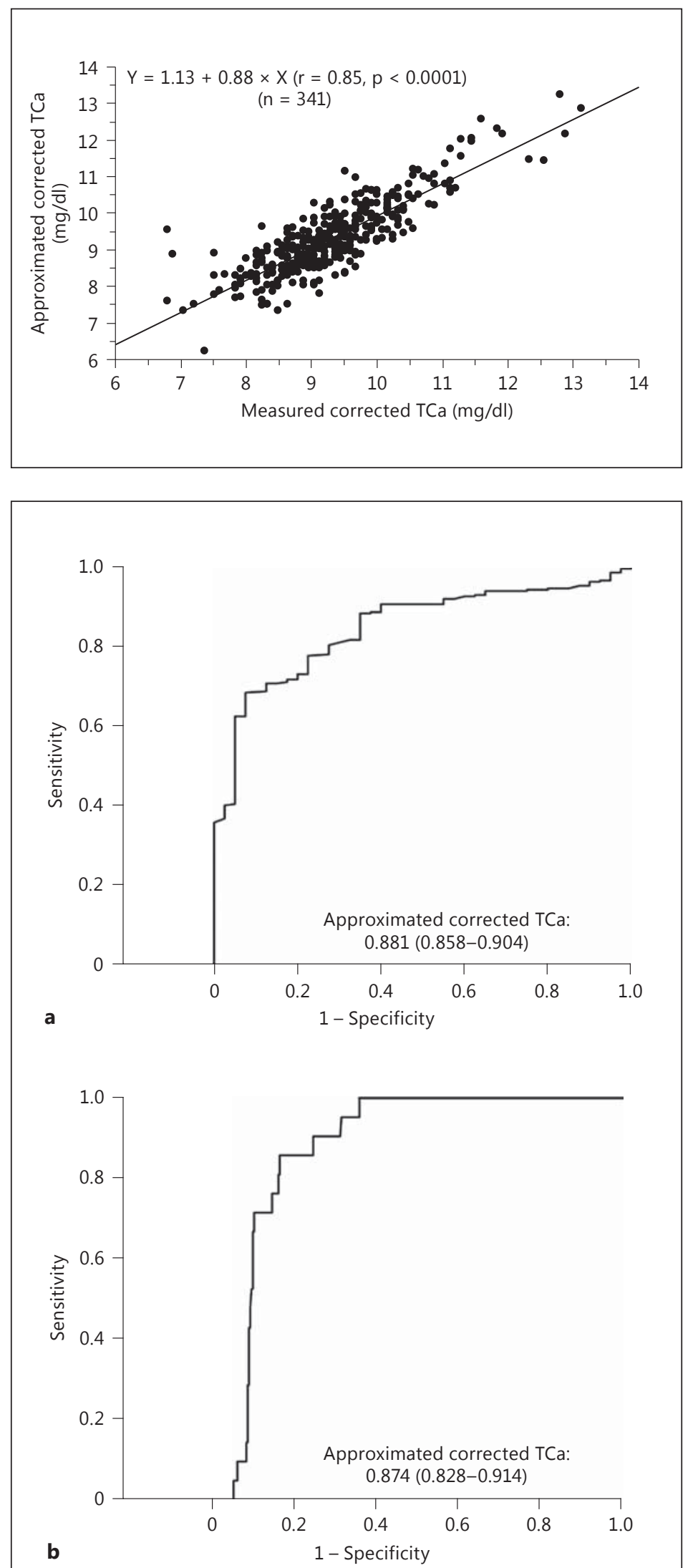
Kaku et al.: Approximation of Corrected Calcium Concentrations in Advanced Chronic Kidney Disease Patients with or without Dialysis Therapy

Table 5. Comparison between measured corrected TCa and predicted corrected TCa values derived from the four previously reported formulas and the approximated corrected TCa in patients with CKD G4 + G5 and CKD G5D, respectively

\begin{tabular}{|c|c|c|c|c|c|c|}
\hline & $\begin{array}{l}\text { Measured } \\
\text { corrected TCa }\end{array}$ & Payne & Jain & Portale & Ferrari & New formula \\
\hline \multicolumn{7}{|l|}{$G 4+G 5$} \\
\hline Mean \pm SD, mg/dl & $9.34 \pm 0.81$ & $8.99 \pm 0.82^{*}$ & $8.10 \pm 0.78^{*}$ & $8.90 \pm 0.78^{*}$ & $9.24 \pm 1.10^{* *}$ & $9.32 \pm 0.84$ \\
\hline ICC & & 0.576 & 0.652 & 0.652 & 0.377 & 0.826 \\
\hline $95 \% \mathrm{CI}$ & & $0.545-0.605$ & $0.626-0.677$ & $0.626-0.677$ & $0.338-0.415$ & $0.812-0.840$ \\
\hline \multicolumn{7}{|l|}{$G 5 D$} \\
\hline Mean \pm SD, mg/dl & $9.32 \pm 0.97$ & $9.43 \pm 1.01$ & $8.44 \pm 0.99 *$ & $9.24 \pm 0.99$ & $9.98 \pm 1.25^{*}$ & $9.33 \pm 1.00$ \\
\hline ICC & & 0.766 & 0.504 & 0.803 & 0.480 & 0.850 \\
\hline $95 \% \mathrm{CI}$ & & $0.719-0.807$ & $0.420-0.579$ & $0.762-0.838$ & $0.394-0.558$ & $0.818-0.877$ \\
\hline
\end{tabular}

corrected TCa and the approximated corrected TCa calculated by using formula $6(\mathrm{r}=0.85$, $\mathrm{p}<0.0001$ ). ROC analysis illustrated that the AUC of approximated corrected TCa for detection of measured corrected $\mathrm{TCa} \geq 8.4 \mathrm{mg} / \mathrm{dl}$ and $\leq 10.4 \mathrm{mg} / \mathrm{dl}$ was 0.881 and 0.874 , respectively (fig. 4). Furthermore, we compared the measured corrected TCa with the predicted corrected TCa derived from the four previously reported formulas as well as the approximated corrected TCa in each of the CKD G4 + G5 and G5D patient groups (table 5). In the analysis of CKD G4 + G5, the values of predicted corrected TCa derived from all the previously reported formulas were significantly lower than those of the measured corrected TCa values, despite the absence of a significant difference between the measured corrected TCa and approximated corrected TCa. The ICC was highest with the new formula derived in this study $(0.826)$ and relatively low with the other previously reported formulas. Furthermore, the values of predicted corrected TCa derived from formulas 2 and 4 were significantly different compared to those of the measured corrected TCa values in the analysis of CKD G5D patients. Similar to the analysis of the CKD G4 + G5 patients, the ICC was also highest with the new formula derived in this study (0.850) compared to the previously reported formulas.

\section{Discussion}

In the present study, we derived a new formula for corrected TCa approximation by using clinical parameters, including pH, serum albumin and P in CKD G4 + G5 patients and serum albumin, $\mathrm{P}$ and $\mathrm{HCO}_{3}{ }^{-}$in CKD G5D patients. Based on the new formulas in this study, a significant linear correlation was observed between measured corrected TCa and the approximated corrected TCa calculated from our derived formula. A high correlation was confirmed by ROC analysis, and each ICC value in this new formula was remarkably higher than those of the previously reported formulas. Therefore, in clinical settings, this simple formula would be useful for approximating corrected TCa values for advanced CKD patients with or without dialysis therapy. This simple formula expresses different degrees of associations between the measured corrected TCa and clinical parameters, such as $\mathrm{pH}$, serum albumin and $\mathrm{P}$ in the CKD $\mathrm{G} 4+\mathrm{G} 5$ patients and serum albumin, $\mathrm{P}$ and $\mathrm{HCO}_{3}{ }^{-}$in the CKD G5D patients. Furthermore, this study clarified the difference in factors for approximating corrected TCa values between patients with CKD G4 + G5 and those with CKD G5D. 
Ca in blood exists in three forms: bound to protein, chelated to serum anions and as free $\mathrm{iCa}^{2+}[17,18]$. Although free $\mathrm{iCa}^{2+}$ is biologically active and considered to be the mostimportant form, these measurements are difficult to obtain and are not performed routinely. If the TCa values are the same in all blood samples, those with lower protein and/or albumin concentrations are suspected to have higher $\mathrm{iCa}^{2+}$ than samples with higher protein and/or albumin concentrations. Indeed, it was recently reported that low albumin concentration causes an underestimation of blood Ca concentration [15]. Therefore, methods for estimating $\mathrm{iCa}^{2+}$ or corrected TCa by using TCa and albumin have been devised $[1,12,13]$. The use of the Payne formula [1], in particular, is widely accepted in the clinical setting. However, this formula was developed to exclude renal patients (i.e., CKD patients) [1], consequently resulting in poor performance $[11,12,14]$. In this study, the lower ICC demonstrated with the Payne formula (CKD G4 + G5: $r=0.576$; CKD G5D: $r=0.766$ ) compared to that with the new formula (CKD $G 4+G 5: r=0.826$; CKD G5D: $r=0.850$ ) is consistent with previous reports $[11,12,14]$. Furthermore, the coefficient of albumin in both new formulas derived from this study was decreased by about one-fourth compared to that of the Payne formula. In CKD patients, the corrected TCa would be affected not only by serum albumin concentrations but also other factors, including $\mathrm{pH}$ and $\mathrm{P}$ in $\mathrm{CKD} \mathrm{G} 4+\mathrm{G} 5$ and $\mathrm{P}$ and $\mathrm{HCO}_{3}{ }^{-}$in CKD G5D. Therefore, the influence of serum albumin on the corrected TCa would be relatively smaller in CKD patients compared to non-CKD patients. In addition to the relationship between the corrected TCa and albumin concentration, the electrical charge of albumin would influence the values of corrected TCa and/or $\mathrm{iCa}^{2+}$. Since the electrical charge of albumin is reported to be correlated with $\mathrm{pH}$ in blood [19], the $\mathrm{pH}$ may directly influence corrected TCa levels by changing the electrical charge of albumin. Because of the decrease in $\mathrm{pH}$ with CKD progression, corrected TCa may potentially increase because of the decreased affinity between $\mathrm{iCa}^{2+}$ in the blood and serum albumin. Low plasma $\mathrm{pH}$ is reported to result in underestimation of the corrected TCa [15]. In addition, the new formula derived from the CKD G4 + G5 patients in this study demonstrates the direct influence of $\mathrm{pH}$ change on corrected TCa. A 1-unit decrease in $\mathrm{pH}$ increases the $\mathrm{iCa}^{2+}$ value by $0.36 \mathrm{mmol} / \mathrm{l}(\mathrm{n}=26)$. This increase corresponds to nearly a $3.0 \mathrm{mg} / \mathrm{dl}$ increase in corrected TCa [20]. According to our new formula, a 1-unit decrease in $\mathrm{pH}$ increases corrected TCa by $4.0 \mathrm{mg} / \mathrm{dl}$; this value is similar to that in a previous report [20]. Since there are no current formulas for predicting the corrected TCa in CKD G4 + G5 patients that include $\mathrm{pH}$, the new formula for approximating corrected TCa is more accurate than the previously reported formulas. On the other hand, the new formula for approximating corrected TCa includes TCa, serum albumin, $\mathrm{P}$ and $\mathrm{HCO}_{3}{ }^{-}$instead of $\mathrm{pH}$ in CKD G5D patients. Regarding the relationship between $\mathrm{iCa}^{2+}$ and $\mathrm{HCO}_{3}{ }^{-}$concentration, it was previously reported that $\mathrm{iCa}^{2+}$ varies inversely with $\mathrm{HCO}_{3}{ }^{-}$in the serum without $\mathrm{pH}$ dependence. A $1 \mathrm{mmol} / \mathrm{l}$ increase in the $\mathrm{HCO}_{3}{ }^{-}$level decreases $\mathrm{iCa}^{2+}$ by $0.0036 \mathrm{mmol} / \mathrm{l}$, which corresponds to the corrected TCa by nearly $0.03 \mathrm{mg} / \mathrm{dl}$ [21]. Our new formula for CKD G5 patients demonstrated that a $1 \mathrm{mmol} / \mathrm{l}$ increase in $\mathrm{HCO}_{3}{ }^{-}$decreases corrected TCa by $0.03-0.05 \mathrm{mg} / \mathrm{dl}$; this value was similar to previous reports. However, the differences in the factors influencing the corrected TCa between patients in CKD G4 + G5 and those in CKD G5D cannot be presently identified and further study is needed.

Furthermore, as to the disorders of bone and mineral metabolism in CKD patients, an association with the fibroblast growth factor-23 (FGF-23)-Klotho endocrine system (bone-kidney-parathyroid endocrine axis) was recently reported [22, 23]. FGF-23 is secreted by bone with increased $\mathrm{P}, 1,25(\mathrm{OH})_{2} \mathrm{D}_{3}$ and parathyroid hormone concentrations. Along with the Klotho/FGF receptor complex, it suppresses $\mathrm{P}$ reabsorption and $1,25(\mathrm{OH})_{2} \mathrm{D}_{3}$ synthesis in the kidney. Therefore, FGF-23 is a phosphaturic hormone and the counter-regulatory hormone to vitamin $\mathrm{D}$ in this axis. In CKD-related bone and mineral dysregulation, Klotho expression declines progressively as FGF-23 expression increases in order to 
maintain Ca-P homeostasis even in the early CKD stages [24]. Finally, in advanced CKD patients, serum $P$ and parathyroid hormone levels increase markedly because of impairment of the urinary phosphaturic ability and decreases in serum $1,25(\mathrm{OH})_{2} \mathrm{D}_{3}$ levels, which consequently induce a corresponding decrease in the serum Ca levels. This may indicate an inverse relationship between serum $\mathrm{P}$ concentration and TCa values in accordance with CKD progression [25]. A method for predicting corrected TCa using not only serum albumin but also serum P concentration (Ferrari formula) has been published [14]. However, in this study, the ICC with the Ferrari formula (CKD G4 + G5: $r=0.377$; CKD G5D: $r=0.480$ ) was relatively lower compared to the new formula (CKD G4 + G5: $r=0.826$; CKD G5D: $r=0.850$ ). The approximated corrected TCa values obtained by using the new formula for both CKD G4 + G5 and CKD G5D patients had superior agreement with measured corrected TCa compared to all the other formulas.

Regarding the limitations of this study, the method of collection of blood samples needs to be initially addressed. In general, $\mathrm{iCa}^{2+}$ concentration measurements and blood gas analysis are performed using arterial blood samples. In the present study, especially in the patients with CKD G4 + G5, we collected venous blood samples and analyzed the relationship between the corrected TCa values based on $\mathrm{iCa}^{2+}$ measurements and clinical parameters including blood gas analysis. Venous $\mathrm{iCa}^{2+}$ concentrations did not differ significantly compared to the arterial $\mathrm{iCa}^{2+}$ measurements $[26,27]$, while the $\mathrm{pH}$ values in the venous samples were lower than those in the arterial samples. Recently, it was reported that arterial $\mathrm{pH}$ is $0.03-0.033$ higher than venous $\mathrm{pH}[28,29]$. Based on these studies, the differences in the approximated corrected TCa values between the arterial and venous samples in the CKD G4 + G5 patients will only be around $0.1 \mathrm{mg} / \mathrm{dl}$ using our formula. Although there is an absolute difference in the approximated corrected TCa values between the arterial and venous samples, this difference might not be as large in the clinical setting. Secondly, advanced-stage CKD patients are mainly followed up at our division, resulting in more blood samples from patients with CKD G5 compared to those with CKD G4 and G5D. However, since this study was performed in patients with altered renal function ranging from CKD G4 to G5D, we considered each blood sample to be different from all the others. Furthermore, our formula for the corrected TCa approximation includes TCa, serum albumin and P concentrations as well as $\mathrm{pH}$ in patients with CKD G4 + G5, and $\mathrm{HCO}_{3}{ }^{-}$in those with CKD G5D. A separate blood gas analyzer measures $\mathrm{pH}$ and $\mathrm{HCO}_{3}{ }^{-}$values. Thus, a formula including $\mathrm{pH}$ or $\mathrm{HCO}_{3}{ }^{-}$measurements might be impractical in a clinical setting. However, in this study we were interested in the influence of changes in the acid-base metabolism on the corrected TCa concentration during the different stages of CKD progression. Therefore, our formula for the corrected TCa approximation, which included $\mathrm{pH}$ and $\mathrm{HCO}_{3}{ }^{-}$measurements, was subsequently devised. A new formula that excludes $\mathrm{pH}$ and $\mathrm{HCO}_{3}{ }^{-}$measurements is necessary for future further examinations.

In conclusion, we have devised a simple formula for the approximation of corrected TCa in patient with CKD G4 + G5 using serum albumin, $\mathrm{P}$ levels as well as $\mathrm{pH}$ values. For patients with G5D, we used serum albumin, $\mathrm{P}$ and $\mathrm{HCO}_{3}{ }^{-}$levels. Compared to other formulas, the approximated corrected TCa value calculated from the new formula for patients with CKD G4 + G5 and CKD G5D demonstrates superior agreement with the measured corrected TCa.

\section{Disclosure Statement}

The authors have no conflicts of interest to declare. 
Kaku et al.: Approximation of Corrected Calcium Concentrations in Advanced Chronic Kidney Disease Patients with or without Dialysis Therapy

\section{References}

1 Payne RB, Little AJ, Williams RB, Milner JR: Interpretation of serum calcium in patients with abnormal serum proteins. Br Med J 1973;4:643-646.

2 Moe SM, Drueke T, Lameire N, Eknoyan G: Chronic kidney disease-mineral-bone disorder: a new paradigm. Adv Chronic Kidney Dis 2007;14:3-12.

- Vanholder R, Massy Z, Argiles A, Spasovski G, Verbeke F, Lameire N; European Uremic Toxin Work Group: Chronic kidney disease as cause of cardiovascular morbidity and mortality. Nephrol Dial Transplant 2005;20: 1048-1056.

4 Go AS, Chertow GM, Fan D, McCulloch CE, Hsu CY: Chronic kidney disease and the risks of death, cardiovascular events, and hospitalization. N Engl J Med 2004;351:1296-1305.

5 Block GA, Hubert-Shearon TE, Levine NW, Port FK: Association of serum phosphorus and calcium $\times$ phosphate product with mortality risk in chronic hemodialysis patients: a national study. Am J Kidney Dis 1998;31:607-617.

6 Teng M, Wolf M, Ofsthun MN, Lazarus JM, Heman MA, Camargo CA Jr, Thadhani R: Activated injectable vitamin D and hemodialysis survival: a historical cohort study. J Am Soc Nephrol 2005;16:1115-1125.

7 Natoli JL, Boer R, Nathanson BH, Miller RM, Chiroli S, Goodman WG, Belozeroff V: Is there an association between elevated or low serum levels of phosphorus, parathyroid hormone, and calcium and mortality in patients with end stage renal disease? A meta-analysis. BMC Nephrol 2013;14:88-103.

-8 National Kidney Foundation: K/DOQI clinical practice guidelines for bone metabolism and disease in chronic kidney disease. Am J Kidney Dis 2003;42(suppl 3):S1-S201.

-9 Kidney Disease: Improving Global Outcomes (KDIGO) CKD-MBD Work Group: KDIGO clinical practice guideline for the diagnosis, evaluation, prevention, and treatment of chronic kidney disease-mineral and bone disorder (CKD-MBD). Kidney Int Suppl 2009;113:S1-S130.

$\checkmark 10$ Palmer SC, Hayen A, Macaskill P, Pellegrini F, Craig JC, Elder GJ, Strippoli GF: Serum levels of phosphorus, parathyroid hormone, and calcium and the risks of death and cardiovascular disease in individuals with chronic kidney disease: a systematic review and meta-analysis. JAMA 2011;305:1119-1127.

11 Clase CM, Norman GL, Beecroft ML, Churchill DV: Albumin-corrected calcium and ionized calcium in stable haemodialysis patients. Nephrol Dial Transplant 2000;15:1841-1846.

12 Jain A, Bhayana S, Vlasschaert M, House A: A formula to predict corrected calcium in haemodialysis patients. Nephrol Dial Transplant 2008;23:2884-2888.

13 Portale AA: Blood calcium, phosphorus, and magnesium, in Favus MJ (ed): Primer on the Metabolic Bone Disease and Disorders of Mineral Metabolism. Philadelphia, Lippincott, Williams \& Wilkins, 1999, pp 115-118.

-14 Ferrari P, Singer R, Agarwal A, Hurn A, Townsend MA, Chubb P: Serum phosphate is an important determinant of corrected serum calcium in end-stage kidney disease. Nephrology (Carlton) 2009;14:383-388.

-15 Gauci C, Moranne O, Fouqueray B, de la Faille R, Maruani G, Haymann JP, Jacquot C, Boffa JJ, Flamant M, Rossert J, Urena P, Stengel B, Souberbielle JC, Froissart M, Houillier P; NephroTest Study Group: Pitfalls of measuring total blood calcium in patients with CKD. J Am Soc Nephrol 2008;19:1592-1598.

-16 Matsuo S, Imai E, Horio M, Yasuda Y, Tomita K, Nitta K, Yamagata K, Tomino Y, Yokoyama H, Hishida A; Collaborators developing the Japanese equation for estimated GFR: Revised equations for estimated GFR from serum creatinine in Japan. Am J Kidney Dis 2009;53:982-992.

17 Toribara TY, Terepka AR, Dewey PA: The ultrafiltrable calcium of human serum. I. Ultrafiltration methods and normal values. J Clin Invest 1957;36:738-740.

18 Loken HF, Havel RJ, Gordan GS, Whittington SL: Ultracentrifugal analysis of protein-bound and free calcium in human serum. J Biol Chem 1960;235:3654-3658.

19 Figge J, Rossing TH, Fencl V: The role of serum proteins in acid-base equilibria.J Lab Clin Med 1991;117:453-467.

20 Wang S, McDonnell EH, Sedor FA, Toffaletti JG: pH effects on measurements of ionized calcium and ionized magnesium in blood. Arch Pathol Lab Med 2002;126:947-950.

21 Hughes WS, Aurbach GD, Sharp ME, Marx SJ: The effect of the bicarbonate anion on serum ionized calcium concentration in vitro. J Lab Clin Med 1984;103:93-103.

22 Kuro-O M: Phosphate and Klotho. Kidney Int Suppl 2011;121:S20-S23.

23 Kuro-O M: A phosphate-centric paradigm for pathophysiology and therapy of chronic kidney disease. Kidney Int Suppl (2011) 2013;3:420-426.

24 Hu MC, Shi M, Zhang J, Quinones H, Griffith C, Kuro-O M, Moe OW: Klotho deficiency causes vascular calcification in chronic kidney disease. J Am Soc Nephrol 2011;22:124-136.

$\checkmark 25$ Lehmann M, Mimouni F: Serum phosphate concentration. Effect on serum ionized calcium concentration in vitro. Am J Dis Child 1989;143:1340-1341.

26 Wandrup J, Kancir C, Hyltoft Petersen P: Ionized calcium and acid-base status in arterial and venous whole blood during general anaesthesia. Scand J Clin Lab Invest 1988;48:115-122.

27 Gando S, Tedo I, Kubota M: A comparison of serum ionized calcium in arterial and mixed venous blood during CPR. Ann Emerg Med 1990;19:850-856.

28 Bloom BM, Grundlingh J, Bestwick JP, Harris T: The role of venous blood gas in the emergency department: a systematic review and meta-analysis. Eur J Emerg Med 2014;21:81-88.

-29 Byrne AL, Bennett M, Chatterji R, Symons R, Pace NL, Thomas PS: Peripheral venous and arterial blood gas analysis in adults: are they comparable? A systematic review and meta-analysis. Respirology 2014;19:168175. 